Article

\title{
Alternative Approaches to Food: Community Supported Agriculture in Urban China
}

\author{
Kees Krul ${ }^{2}$ and Peter Ho ${ }^{1,2, *}$ \\ 1 Minzu University of China, No. 27 Zhongguancun South Street, Beijing 100081, China \\ 2 Delft University of Technology, Faculty of Technology, Policy and Management, P.O. Box 5015, \\ 2600 GA Delft, The Netherlands; K.Krul-1@tudelft.nl \\ * Correspondence: p.p.s.ho@tudelft.nl; Tel.: +31-15-27-82479
}

Academic Editor: Han Wiskerke

Received: 16 February 2017; Accepted: 10 May 2017; Published: 18 May 2017

\begin{abstract}
One of the most remarkable features of China's development path is its large-scale and fast-paced urbanization. As cities already accommodate more than half of China's population, new challenges to urban food systems have emerged concurrently. Concerns over environmental degradation and food safety have provoked growing dissatisfaction with China's food regime. Amidst these concerns, the aim of this paper is to study the role of new and alternative approaches to food, focusing in on the question of how community supported agriculture (CSA) can deal with the food-related issues emerging from China's development. The paper adopts Granovetter's notions of social embeddedness to describe CSA's relational role in consumer-farmer dynamics, as well as the structural role within its broader relational context. Empirical data is drawn from surveys distributed among CSA farms, and interviews with key stakeholders in the Chinese CSA movement. The study finds that the model of CSA demonstrates an innovative approach to deal with food safety issues, address sustainability, and operate in an environment where future food demands are most critical. Although the movement's structural embeddedness is bound by several limitations and contradictions, it is argued that the CSA model offers important insights and adds value into ameliorating China's food systems.
\end{abstract}

Keywords: community supported agriculture; alternative food systems; food safety; embeddedness; China

\section{Introduction}

China's level of urbanization remains unprecedented, evident in the myriad of changes within the urban fringe, which includes the construction of massive train stations, golf courses, and high-end condominiums. As cities increasingly accommodate more of China's population, urbanization is posing new challenges to food systems: the rapid loss of farmland [1,2], environmental degradation and pollution [3], and the changing and more demanding diets of urban citizens [4]. While continuous food safety scandals are evident, China's policy of self-sufficiency has become harder to sustain [5]. More than half of the Chinese population is now living in cities, and it is expected that the trend of urbanization will continue for the subsequent decades. It is, therefore, important to examine new approaches that can deal with the pr45essures emerging from China's development path.

Community supported agriculture (CSA) is an alternative farming model that only recently appeared in China, and which in this study is conceptualized as an alternative food system (AFS). Food systems encompass a series of processes, which entails everything which is required to deliver food from the farmer to the consumer. Elements of the food system include seeding, cultivation, packaging, distribution and, ultimately, the consumption of food [6]. The CSA model shifts from the conventional agricultural system by promoting local food and reconfiguring the relation between the producer and 
consumer: they partner to share the risks and benefits of the farm operations [7]. While the concept was realized in the United States during the 1980s, and has since received scholarly attention, much remains unknown about CSA on China's soil.

Similar to previous studies on alternative food systems, the focus of the study will not revolve around the actual output of food produced by the CSAs. Instead, this study's contribution hinges on its main aim to examine the role of alternative food systems amidst emerging pressures from rapid urbanization. While most studies on AFSs tend to study the phenomenon by focusing on its own context, this study places CSA within the wider context that it is configured within, and examines how it may complement China's conventional food systems. Therefore, the following question is addressed: What is the added value of the CSA model in dealing with food-related issues in China's development? By doing so, references are made to the "conventional" food system and its concerns. Granovetter's [8] notion of embeddedness is adopted to describe CSA's relational role in consumer-farmer dynamics, as well as its structural role within its broader relational context. The latter regards CSA as something that is "embedded" in its larger environment, in this study referred to as the socio-spatial context. While the study finds that structural embeddedness of the model in China is bound by several limitations and contradictions, this paper will argue that the model of CSA offers new insights and solutions to deal with emerging issues in China's food system.

This paper is organized as follows: The remainder of this introduction describes China's development and how it has spawned new issues in the food system, as well as the responses that have emerged from those issues; The Section 2 outlines this paper's methodology and theories. The Section 3 presents the empirical data; The Section 4 comprises an analysis examining relational and structural embeddedness of the CSA model; In the concluding section, findings are summarized and final considerations are provided.

\subsection{The Urban Food Desert}

During the post-Maoist era from 1978 onwards, China entered a new phase where its centrally-planned economy underwent restructuring towards an internationally-oriented and competitive market economy. As a result, the accumulation of capital and urban growth was facilitated by a "spatial fix" [9], i.e., a massive wave of rural migrants willing to work for minimal wages in the city. Ongoing urbanization led to China's urban population exceeding its rural counterparts for the first time in history in 2011 [10]. While economic and urban growth has been spatially concentrated along the eastern coast for many years, recent developments, such as China's "new urbanization" policy [11], aim to stimulate urban growth in inland, or "second-tier", cities as well. China now hosts several "megacities", and the Pearl River Delta has recently become the largest and most populated urban area in the world [12]. As China's cities continue to grow in both economic activity and population, the urge to expand spatially exerts considerable pressure on its urban fringes and has already induced irreversible changes on China's socio-spatial environment [13].

China's urban transformation has also raised critical concerns, including that of food security, despite a broad consensus that China has been successful in securing its availability of food [14]. With the exception of the Great Famine, since the 1950s China has-particularly after 1978-become successful in securing food supplies by placing emphasis on local self-sufficiency [15]. Part of the success can be ascribed to a technical "fix", which led to mechanized agriculture, intensified use of chemical fertilizers, and improved irrigation and farm equipment [15]. Current national policies continue to strive for self-sufficiency, with targets to satisfy 95 percent of domestic consumption of a range of crops and staple foods [16]. Policy implementations, such as the Comprehensive Agricultural Development program and the Household Responsibility System, have alleviated the problem of food inadequacy for the majority of the Chinese population [4]. However, there are remaining and emerging issues in China's urban food systems that are closely tied to urbanization. Three main issues are identified in this paper. 
A paramount challenge to China's food systems, especially in urban areas, is that of food safety. China has been the focus of many food safety issues and scandals in recent years, often covered and revealed by Chinese media [16]. As abovementioned, the availability of food has significantly improved, but this has been partly achieved by an intensified usage of chemicals and fertilizers. Chinese farmers continue to apply excessive amounts of chemical fertilizers, which results in high amounts of harmful substances in food, posing a long-term threat to the quality and safety of edible products for human health [17]. Other issues occur in the off-farming processing and the distribution of food, in particular, the use of additives. While state authorities have recognized food safety issues, China's many small-scale farmers and scattered channels of food distribution have made regulating the food system a dreadful task [18]. As a result, it has become harder to trace the origins of food production and evaluate the degree of safety in its methods.

The second challenge rooted in China's urban food system are the high rates of population growth and dietary changes. While demographic changes have increased domestic food demands, the changing diet of the urban population has, in recent decades, also posed a serious problem [19]. The Chinese diet consists of a wide variety of agricultural products, such as staple foods, vegetables, fruits, livestock and aquatic products. Demand for all of these commodities has increased, characterized by a general shift from a strict staple food diet to a more diversified diet, including a higher meat consumption [17]. The changing and increasingly demanding diet of Chinese urbanites require higher amounts of resources, such as water, land, and grain [17].

The third challenge relates to China's reduced and degraded volumes of water and land resources. Lester Brown [20] in 1995 estimated that if the trend of farmland loss continues in parallel with rising food demands, China would be incapable feeding itself by 2030 (it should be noted that Brown's thesis has been challenged by many scholars on numerous grounds; see also [21] (pp. 8-9). However, while contested, it sparked a debate between Chinese agriculturalists and, consequently, more state efforts that aimed to preserve China's standing resources). Despite numerous state efforts, the loss of farmland has continued and currently China's per capita averages of water $\left(2200 \mathrm{~m}^{3}\right)$ and land $(0.1 \mathrm{ha})$ resources are far below the global averages of $7300 \mathrm{~m}^{3}$ and 0.25 ha, respectively [22]. Furthermore, China's water and land resources have also suffered from environmental pollution. Soil contamination, such as heavy metal pollution, not only poses a threat to the ecological environment, but also to the safety of edible products [13]. Further issues occur due to pollution in water caused by industrial contaminants dumped into rivers and lakes, chemical pesticide runoff from crop fields, and human waste and garbage disposed into the waterways [17]. Taken together, urbanization-induced pollution and degradation pose a serious threat because agriculture depends heavily on the integrity of the ecosystem, in addition to it jeopardizing food security.

\subsection{Responses in the Urban Context}

Emerging issues and dissatisfaction with the food system has given rise to new civil society-led approaches to organize the food system. As the word "alternative" suggests, AFSs surface in a context where there is another prevailing food system-often dichotomously described as the dominant, mainstream, or conventional system (in this study, hereafter, the term "conventional" is used). In light of recent events such as the global financial crisis that culminated in a "global food crisis" [15], a growing number of observers and food activists have questioned the sustainability of the conventional food system; e.g., [23-26]. In challenging the conventional food system, actors use their local environment as a space for change by initiating AFSs, such as farmers' markets, community gardens, and CSA. Such movements have recently become more visible in China as well [26].

The model of CSA is characterized by a community that supports the farm operations so that the farm becomes community-owned or stewarded [27]. While the "supportive" aspect can entail physical labor, it is mostly on a subscription basis that members participate. They make an advance payment in the form of shares to cover the anticipated cost [7]. In return, members receive deliveries directly from the farm at frequent intervals. In this model, the members share both the risks of poor harvests and 
the benefits of successful harvests [7]. The first CSAs have their roots in the United States starting from the 1980s, and empirical studies still heavily draw from European and North-American contexts. The concept began to receive more scholarly attention outside this context with the recent introduction of CSA in China [16,28].

Emerging issues and dissatisfaction with the conventional food system, most notably that of food safety, has motivated China's civil society to initiate new approaches to how food systems should be organized [18]. The majority of these initiatives occurred in China's urban and peri-urban areas, but a few have been initiated in more remote areas as well [29]. A study on urban agriculture in Minhang (Shanghai), have shown that such initiatives can be successful in creating jobs, enhancing food safety, and improving the quality of farmland [30]. Studies observing the emergence of Chinese CSAs remain limited because the first CSA appeared only in 2008, and the phenomenon remains largely conceptualized within the Western context.

It is widely recognized that the first Chinese farm to adopt the CSA model is Little Donkey Farm [28], located in the northwest of Beijing's Haidian district (while two farms in this study claimed to have established their farm in 2004, they did not adopt the CSA model yet. Little Donkey Farm is the first farm in China to claim having adopted the CSA model. After Little Donkey Farm was established in 2008, and has received much attention since then, the CSA movement has quickly developed throughout China. Shi Yan, oral communication). The farm and its initiator, Shi Yan, have received much scholarly and media attention since then. Shi Yan herself has also contributed several academic articles [26,28]. Similar to CSAs in other countries, Shi et al. [28] have identified the Chinese urban middle class as an important driver to CSA as they constitute a high proportion of the consumers and producers. Consumers with a middle-class background tend to have an expanded discretionary income and, therefore, more resources to spend on food [28]. Cheng and Shi [26] find that the motivation to start a CSA in China is diverse: some farms have been established due to food safety concerns, select ones are inspired by the principles of organic agriculture or biodynamic farming, while others have risen out of a partnership with research institutes.

As noted by Si et al. [16], this has led to some inconsistency between consumers and initiators. For example, Scott et al. [18] find that consumers of CSA are primarily motivated by food safety, and show limited concerns about improving the environment or the livelihood of the local peasants. In a study on four types of AFNs in China including CSA, Si et al. [16] have examined the nature of alternative food networks (AFNs) and compared it with their Western counterparts. The study finds that Chinese AFNs share some similarities with Western types, especially in terms of strong urban middle-class participation. However, Chinese AFNs differ in the way that they surface in the context of widespread food safety concerns and tend to be more driven by consumers. Another significant finding is that Chinese AFNs do not directly oppose the dominant food system, but aim to complement them instead [16]. Two contributions by Song et al. [29] and Buckley [31] provide detailed analyses of two CSA farms in Beijing and Guangxi. The studies find that the development of CSA was paired with numerous benefits: young people returned to the farm, farmers gained more access to markets, and incomes have increased significantly. However, CSAs still face considerable challenges, such as soil and water contamination, institutional barriers, and skeptical consumers [29,31]. Finally, while it is found that CSA caters to only a "small niche group" ([31], p. 98), Si et al. [16] conclude that the inclusion of local peasants in the construction of AFNs remains low.

\section{Materials and Methods}

\subsection{Methodology}

The aim of this study is to examine the role of alternative food systems amidst high levels of urbanization. Satisfying this objective, the study's methodology is guided by mixed-methods [32], i.e., a combination of both qualitative and quantitative methods. The findings are based on the existing literature, complemented with empirical data consisting of survey and interview data collected from 
CSA farms and stakeholders across China in spring 2015. During the field study, the authors were provided with a document of CSA farms compiled by China's national CSA network (zhongguo dalu shehui nongye) that lists 122 farms (as we will see later in this paper, the number of enlisted farms is considerably lower than the estimates of key stakeholders, who estimate that there are currently over 500 CSA farms in China. This (unofficial) figure is higher because not all farms may opt to be included in the national CSA network or only partly adhere to the CSA model). Although only locations and names were listed, online searches were performed to gather additional contact details as most CSAs have a presence on Chinese online platforms like Weibo and WeChat. Farms were then contacted either via telephone, e-mail, Weibo or WeChat. Fifteen CSA farms in four different provinces were willing to participate in the study (Table 1).

Table 1. Survey respondents.

\begin{tabular}{cccc}
\hline No. & Location & Year Established & Position of Respondent \\
\hline 1 & Beijing & 2012 & - \\
2 & Beijing & 2004 & Manager \\
3 & Kunshan & 2012 & Marketing director \\
4 & Beijing & 2013 & Operations manager \\
5 & Beijing & 2012 & Partner \\
6 & Fuzhuo & 2011 & Coordinator \\
7 & Beijing & 2011 & Sales manager \\
8 & Chengdu & 2009 & Farmer \\
9 & Zhejiang & 2011 & Farm owner \\
10 & Beijing & 2009 & - \\
11 & Beijing & 2008 & Manager \\
12 & Beijing & 2004 & Farm owner \\
13 & Chengdu & 2013 & Leader \\
14 & Beijing & - & Farm owner \\
15 & Beijing & 2010 & Farmer \\
\hline
\end{tabular}

Respondents were asked their preferred interview method (Internet survey, telephone survey, and site visit), with a majority (11) preferring the Internet survey. While the number of surveys is low, this is, to the best of our knowledge, the first study on Chinese CSA that uses the survey method in an attempt to gain more quantitative insights. Furthermore, the (online) survey was found to be an appropriate method as China's CSA farms are scattered across China's vast territory, and farms located in peri-urban areas are less accessible. Given that farmers and managers are usually occupied with daily farming duties, the online survey also allowed respondents to complete the questionnaire in their own time, and at their own place and pace [33].

To increase data reliability and validity, the survey was complemented with site observations at Little Donkey Farm and semi-structured interviews with key stakeholders of the Chinese CSA movement. This was necessary because the survey primarily rests on farmers' perceptions. In this context, it is imaginable that when asked, for instance, about farmland's conditions or on product quality, answers may be overstated or risks underestimated. At this point, additional research to more comprehensively assess the quality and safety of CSA products is required, which also includes the perceptions of consumers or retailers. For our research, interviewees include Wen Tiejun, an agricultural economist and the initiator of the New Rural Reconstruction movement responsible for establishing Little Donkey Farm; Shi Yan, the founder of the first CSA farm in China who, together with her husband, started two other Beijing-based CSAs; and Zhang Lanying, director of the Liang Shuming Rural Reconstruction Center (the names are disclosed with permission of the interviewees). The interviewees also include two representatives from a Beijing-based environmental NGO called Green Beagle. Each interview lasted for at least $90 \mathrm{~min}$. As some interviews were conducted at the end of the field study period, earlier findings of the survey were also discussed and reflected upon. This allowed for valuable additional qualitative insights that could not be obtained with the survey. 


\subsection{Conceptual and Theoretical Framework}

The concept of embeddedness is considered a useful theoretical device to describe the role of CSA to the urban food system. The concept was first coined by Karl Polanyi [34], who argued that economic relations are constructed and influenced by their wider social-institutional environment [35]. Rather than regarding the market as the sole instrument that determines economic transactions, Polanyi [34] claimed that social institutions, such as religion and the government, are equally important, i.e., economic transactions are "embedded" in social practices and networks. Granovetter [8] provided further interpretation to Polanyi's thought and put forward social embeddedness to describe the interaction between economic activities and social behavior. Here, Granovetter [8] treats trust as an absolute necessity for economic relations to occur, which enables social relations to substitute formally arranged institutions to a certain extent. With a strong emphasis on social relations, the theory of social embeddedness contrasts with more utilitarian approaches that have merely focused on the economic rationality of actors [36].

Embeddedness has become widely adopted in studies describing the phenomenon of AFSs $[37,38]$. Particularly because it characterizes AFSs apart from conventional food systems while underlining social ties, trust, reciprocity, and other non-economic components in the transactions of food [37,39]. Thereby, embeddedness has promoted moral considerations in economic behavior and the willingness of actors to weight social, ethical, safety, or environmental incentives against financial ones [35]. This is of value for this study because, as shown in this study's findings, consumers are willing to pay a relatively higher price for CSA products.

Granovetter [8] has made an important distinction between two types of embeddedness: relational and structural embeddedness. Relational embeddedness applies to economic actors and involves the personal relations among them [40]. Given the short and localized supply chain that CSA seeks to pursue, relational embeddedness in this study relates mostly to the direct interactions between the two most dominant actors of CSA: the consumer and farmer. While Granovetter was less clear what structural embeddedness precisely entails [41], it is clear that the concept transcends interpersonal relations and takes into account the broader relational context to which actors belong [40]. In a study on food community networks, Migliore et al. ([37], p. 31) define the process of structural embeddedness whereby "structural mechanisms are established in which the behavior and results of whole groups of people affect and promote a broader relational context". Here, this study draws on the assumption that any type of food system is socially, spatially, and ecologically embedded in their respective locations [35]. Situated in China's urban areas, this study approaches structural embeddedness of Chinese CSAs as follows: socially, which regards CSA as part of a broader social movement, and spatially, which regards CSA as a local food movement that interacts with its immediate surroundings. Recognizing their simultaneous interaction in reality, this study puts forward "socio-spatial" as an overarching term to account for the broader and multi-dimensional context in which CSAs are embedded (socio-spatial is adopted in this paper as a term to describe the simultaneous interaction between society and its spatial environment. The term is widely used in urban sociology and geography, and assumes that social space operates as both a product and a producer of changes in the metropolitan environment ([42], p. 394)).

\section{Results}

\subsection{Motivating CSA's Rapid Emergence}

"I mean when you talk about 'good' food it means the practice, the taste, the flavor, the nutrition". -Shi, 24 March 2015, I-2 \#1

As empirical studies on China's CSAs are scarce, this section first introduces several identifying characteristics of Chinese CSAs as derived from the survey data, which support explaining CSA's rapid emergence. The majority of farmers involved in the Chinese CSA movement can be considered to 
be "new" farmers (xinxing nongmin), in contrast to "local" farmers (dangdi nongmin). Approximately two-thirds of the respondents in this study identified themselves as "new" farmers. This group started farming without a farming background and consists mostly of young and highly-educated urban citizens. Local farmers are usually older, and since the CSA model is coupled with reduced revenue in the initial years of implementation, leaving them often unable or less willing to change their farming model. For the new farmers, the farm is registered as a company instead of an agricultural cooperative, with farmland typically leased from local farmers and operations supported by the hiring of labor.

All farms included in the survey grow vegetables, but most farms also produce cereals and beans, and about half the farms rear livestock, such as chickens and pigs. Most CSAs can be regarded as small-scale, reflected by their average size of $66 \mathrm{mu}$ (4.4 hectares) land. However, this is still notably higher than the average farm holding in China, which only averages nine mu (0.6 hectares) [43]. The CSAs in this study have an average of 14 employees per farm, which is not necessarily composed of full-time and paid employees, and includes family members, volunteers, and students, as well. Little Donkey Farm, for instance, accommodates students undertaking internships at the farm. The majority of CSAs are spatially configured based on proximity to the city. For example, in Beijing, the majority of CSA farms are located within a 50-kilometer radius around the city center. Urban linkages can be explained not only because both farmers and producers share an urban background, but also because respondents believe that food issues are most critical in urban areas:

"Food in the city is a desert. In cities, especially in big cities, you can't find good food. If you live in a small city or small town and you want to have some good food, you know some relatives, and it is quite easy to find. But in Beijing, it is very hard as even the farmers near Beijing don't raise chickens and they don't even grow food for themselves".

-Shi, 24 March 2015, I-2 \#2

Similar to CSA in other countries, CSA in China deviates from the traditional farming model in several important ways. The model attempts to reconfigure the relation between consumer and producer, promoting a more active role for consumers in the food system. Through active marketing directed at local consumers, CSA establishes a platform that allows for direct interaction between farmer and consumer. At the same time, Chinese CSAs promote organic agriculture, although it is mentioned in interviews that not all Chinese CSAs have adopted an organic model. Although official figures remain elusive, respondents estimate that, currently, over 500 farms have adopted the CSA model in China. The rapid emergence of CSA in China can be attributed to early efforts put forward by the New Rural Reconstruction (NRR) movement (xin xiangcun jianshe) led by Wen Tiejun. Wen adopts a critical attitude towards the state-led approach that has taken place in the Chinese countryside over the past decades:

"The industrialized countryside was set up, meaning that the purpose of agriculture was for business and markets while making agriculture more chemicalized with the use of a lot of pesticides".

-Wen, 31 March 2015, I-3 \#1

Standing against this approach, the NRR movement warned that a "rural crisis" has unfolded within the Chinese countryside. In addition to the environmental degradation and health issues stemming from the intensified use of chemicals, it is further argued that the state approach to agriculture has triggered new social and economic problems. The emphasis on low-priced agricultural products, for instance, has given way to what Shi Yan described as the "scissors gap":

"When the prices of raw materials and farming products are lowered, it can provide the urban population with lower food prices. In contrast, farmers have become the lower-priced labor for urbanization. That's why the conventional farmers can't survive".

—Shi, 24 March 2015, I-2 \#3 
Indeed, the NRR posit that farmers are marginalized in China's current food regime, which is evident in the massive rural-to-urban migration and the widening gap between China's urban and rural population. Therefore, the NRR actively seeks new approaches in both the production and marketing process to strive for more equity and sustainability in China's food system. Rather than "capitalized" or "industrialized" agriculture, Wen aims for "socialized" agriculture: embedding social capital into agriculture to shape local, small-scale, traditional and decentralized farms. By doing so, the interviewees emphasize that it is not the government, but the people, and especially China's middle class, that should take responsibility for this change. In 2003, the NRR went into China's countryside to meet with farmers and discuss new directions for agriculture in the country. After that, the NRR established cooperatives and taught local farmers new and alternative approaches, such as organic farming. When the NRR set up ten cooperatives in different provinces as a pilot project, their aim was to implement an organic farming model. However, difficulties surfaced when the cooperatives could not sell their products due to low consumer demand. In turn, NRR's response was to publicize the concept of organic agriculture to the Chinese public:

"We go into the city for consumer campaigning for organic products, starting in 2005. We are trying to establish some sites for tourism, get citizens together to observe what is happening in the village, and how they operate as an organic producer".

-Wen, 31 March 2015, I-3 \#2

This illustrates that NRR not only requires farmers' participation, but also actively seeks to engage consumers in bridging farmers. Against this backdrop, in 2008 the NRR, through a partnership with Renmin University and support from the local government, pioneered China's first CSA farm. While interviewees affiliated with the NRR movement strongly emphasize ideological motives for promoting CSA, more pragmatic motivations to explain its rapid emergence in China are found by the survey respondents (Figure 1). Above all other purposes, health concerns are marked as the most important reason to start a CSA farm. Closely related, it is also believed that the main asset of CSA products over conventional food system products is safety (Figure 2). Given the prevalence of many notorious food scandals in China, the promise of food safety in products is an important contributing factor for CSA's emergence.

The explanation for the rapid emergence of CSA appears as an amalgamation of personal concerns, such as food safety and health issues, dissatisfaction with the conventional food system, and overarching ideologies concerning the engineering of food systems. The increasing presence of CSA in China is paralleled with a positive development trend in food production: the majority of respondents see a steady annual increase of their production and most CSAs have a desire to expand their production activities. Furthermore, frequent coverage of CSA by both Chinese and foreign media illustrates rising interest in the alternative farming model. However, it should be noted that none of the respondents aspires to popularize the CSA movement or make it "mainstream". Instead, their primary aim is to reach out to a larger group of practitioners and introduce more diversity to the conventional food system, rather than oppose it, as illustrated with the following example:

"You can replace all the tractors but it's good to keep some donkeys. Because maybe at one point there will be no more gas. So it is good to keep the donkeys. It is good to be diversified, it's a way that can reduce risk".

-Shi, 24 March 2015, I-2 \#4

Considering the discussion thus far, the subsequent two sections examine how these motivations and intentions have shaped China's CSA movement with connection to the urban food system. 
Question 1. What is your motivation to engage in CSA?

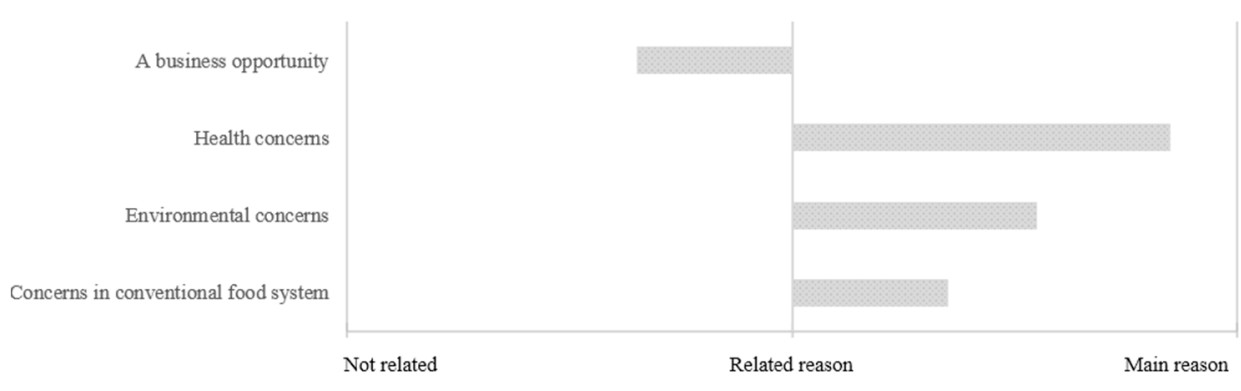

Figure 1. Motivation to engage in CSA $(n=15)$.

Question 2. What is a main asset of your products compared to those from conventional food systems?

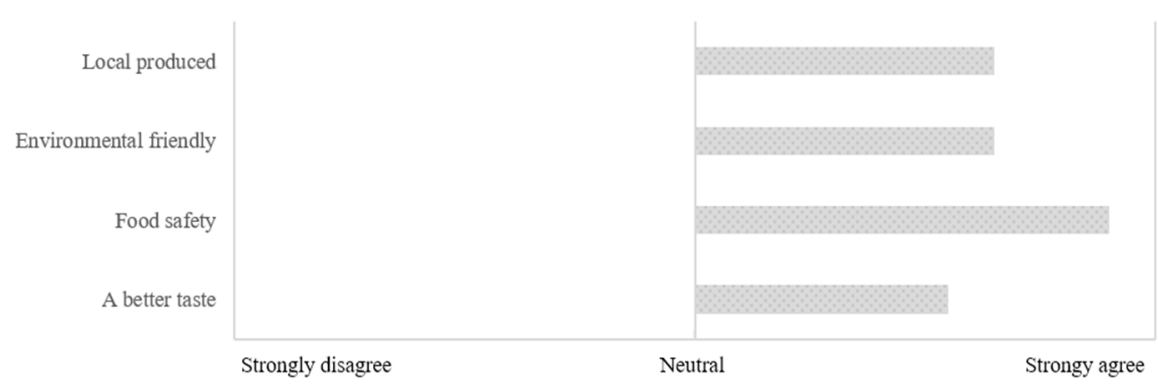

Figure 2. Main asset of CSA products $(n=15)$.

\subsection{From the Farm ...}

The food system begins with the production of food. In addition to desirable tastes and the use of a local, environmentally-friendly production method, food safety is regarded as the most valuable asset by CSA farmers. The latter is achieved through organic farming practices without the use of inorganic pesticides and chemicals, and facilitated through a minimal supply chain that directly connects producer and consumer. While the safety of products in the conventional food system is guaranteed through certification labels issued by formal institutions, CSAs do not use a certification and have no intention of getting one. It is explained that such an approach does not necessarily enhance consumer trust and is found to be cumbersome and expensive. Instead, CSAs engage in more informal ways of verification. The NRR has started promoting the participatory guarantee system (PGS) (PGS is promoted by the International Federation of Organic Agriculture Movements (IFOAM) as a 'locally focused quality assurance system' (for further reading see [44])) which encourages direct participation of consumers and producers in verifying product quality. The NRR is also promoting a self-regulatory system in the form of a coalition consisting of organic farmers, where farmers evaluate each other's adherence to organic farming principles. Finally, the farms strive to build trust as consumers and members are encouraged to visit and assess the farm operations themselves.

Environmental conditions at the farm site are also an important consideration in the food system. Farming systems are largely reliant on the ecosystem that determines much of the product quality, where favorable conditions can significantly enhance the production and safety. At the same time, farming also has an immediate impact on the local ecology. Respondents indicate that soil and water quality is favorable, and show a moderate appreciation for the quality of the air (Figure 3). Regarding pollution, soil and water contamination are also not considered an issue, while air pollution and climate change are considered environmental factors that slightly affect production (Figure 4). However, some respondents do admit that these issues could impact the safety of their products. Environmental issues are more pervasive in areas closer to the city, as urban sprawl and industrialization often result in more 
pollution, such as waste disposal. Representatives from an environmental NGO demonstrated their concerns about the environmental conditions in which CSAs are operating. Contrary to the view of many CSA respondents, they believe that issues, such as water pollution, heavy metal contamination, and garbage disposal have serious implications on the quality of the food. Their attitude is further reflected in their unwillingness to consume CSA products. Shi argued that while acknowledging the operation of CSAs in polluted environments, it is also the aim of many CSA's to ameliorate environmental degradation:

"But why we started organic farming in the beginning is not because the air and water are so good, but because it is polluted and we want to change it. That is the meaning of organic farming. People should understand, you do organic farming to make a change".

—Shi, 24 March 2015, I-2 \#5

Question 3. How do you assess the environmental conditions around your farm?

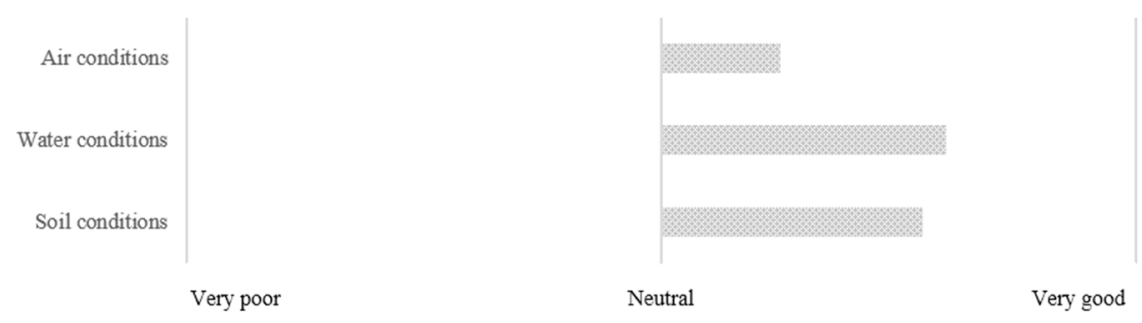

Figure 3. Perception of environmental conditions $(n=15)$.

Question 4. Does your food production gets affected by the following factors:

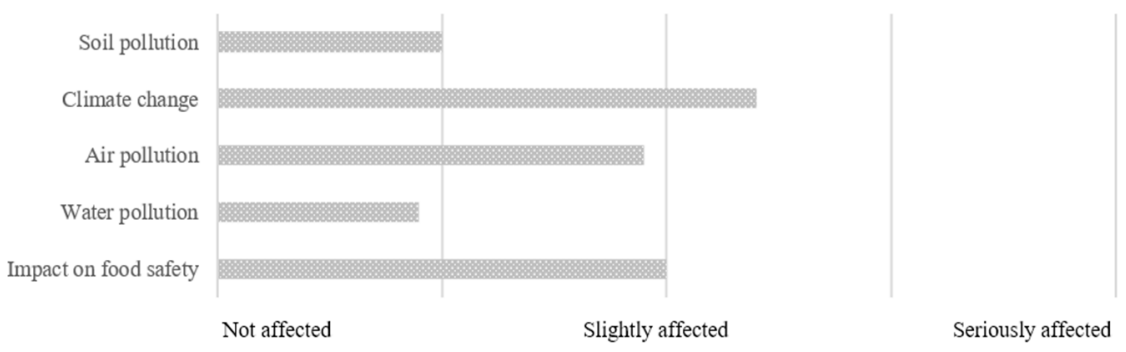

Figure 4. Constraining factors of food production $(n=15)$.

\section{3. ... to the Table}

The second component of the food system relates to the distribution and marketing of food. Here an important consideration is the price of CSA products, which is significantly higher. Respondents estimate that prices are generally three to five times higher than comparable agricultural products offered by conventional markets. These prices are a direct result of the increased costs, as the new farmers usually do not possess agricultural land and need to rent it from local farmers, or in a few instances from the local government. Additionally, hiring labor in combination with labor-intensive farming methods and product delivery to consumers also contribute to higher costs. The high price puts an immediate barrier to economic access of CSA products because not everybody is able or willing to pay a higher price for their food. Therefore, the clientele of CSA, similar to its producers, is middle-high income in addition to being largely urban and well-educated, with a strong demand for safe and healthy produce. Consequently, the movement has sometimes been affiliated with an "elitist" character and is received with skepticism from some local farmers and consumers who do not see the 
need for alternative practices, such as CSA and organic agriculture. For instance, when Little Donkey Farm was established, the largest challenge Wen faced was how to develop trust among local citizens.

While the groups of producers and consumers consist of a small and relatively homogenous fraction of China's population, Chinese CSAs employ diverse and innovative systems to distribute their products to customers. All farms in this study operate a delivery system which distributes their products directly to the client. This is frequently complemented with farmers' markets and pick-up points where consumers and members can collect their products. The Beijing farmers' market, for instance, usually takes place on the weekend at rotating venues that are announced on Weibo and Facebook. Almost half of the farms in this study also employ online channels for marketing and sales purposes, usually through their websites or on the selling platform Taobao. During a site visit to Little Donkey Farm, a poster was observed displaying QR codes that could be scanned using a mobile phone and direct their users to the online platforms. Indeed, China's CSAs are active Internet users, and it is common for farms to maintain a website or blog and post regular updates. In fewer instances, products are distributed through small shops and restaurants, buying clubs or farm shops.

\subsection{Challenges and Future Perceptions}

Given that China's CSA movement is still in its initial phase, the final part of the survey and interviews asked how respondents felt about current trends and remaining challenges. Respondents indicate that the high operation costs are their most important challenge (Figure 5). As mentioned earlier, these costs are mostly an outcome of renting land and hiring labor to sustain the labor-intensive farming practices. Hiring labor is further complicated as some CSAs indicate that they rely on temporary workers, such as interns, while other CSAs indicate difficulty in recruiting local farmers. Although the products are sold at a premium price compared to conventional products, respondents claim that the low revenues are another important challenge. Other challenges, although of lesser significance, include land insecurity, environmental conditions, and urban sprawl. Land insecurity remains a challenge since most CSAs rent their land with a lease term of no longer than ten years. In two cases, land was rented from the local government but, again, with a short lease term (five and ten years). These farms are exceptional cases as government support remains low, and only a few farms received governmental support. Urban sprawl around the farm also poses challenges to farming, as it results in changing environmental conditions and pollution.

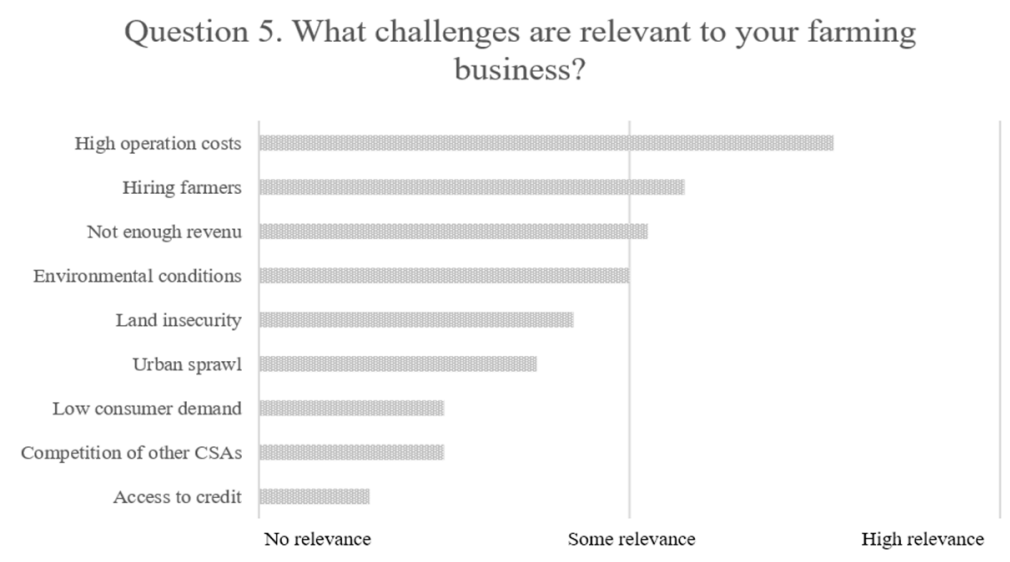

Figure 5. Relevant challenges (based on average score, $n=15$ ).

Representatives of the NRR movement expect that the growing trend of CSA is likely to continue in the future. Shi argued that with the continuous food scandals covered in Chinese media, the model is almost self-promoting. Another interviewee argued that because of China's rising middle class-a key driver for CSA - further demands in the future could also be anticipated. However, the alternative farming model currently only constitutes a tiny fraction of China's food system, catering to a specific 
segment of China's population. Hence, its contribution regarding quantity is negligible. Since CSA products do not have a certification, distributing the products through formal markets is another limitation. With this in consideration, it is important to stress that the aim of many CSAs is not limited to the production of safe food. The majority of the farmers in this study feel that CSA can help to create more awareness about environmental and rural issues, re-establish trust between consumers and producers, and make urban dwellers more interested in agriculture. Many farms also become spaces for education and tourism, as they host activities and rent out plots of farmland for urban citizens, with on-site farm shops and restaurants. Other farms collaborate with universities for scientific purposes or engage in partnerships with the local government.

\section{Discussion}

\subsection{Relational Embeddedness: Consumer and Producer Relations}

Mechanisms that aim to strengthen and reconfigure the relationship between consumers and farmers are evident in the production, marketing and distribution activities of Chinese CSAs. Contrary to the conventional farming model where consumers adopt a more passive role, the model of CSA allows consumers to become active members and shareholders of the farm. The relationship is further strengthened through a short supply chain, characterized by direct deliveries and face-to-face interaction. Consumers and members are frequently informed about the farming practices through digital platforms, while members are also welcomed to visit the farm. Some farms, like Little Donkey Farm, also distribute working shares where members can rent a plot of land on the farm itself. These relational mechanisms allow for more reciprocal and intimate interactions between consumers and farmers.

Almost exceptional in China's food system, the model has managed to building trustworthiness for delivering healthy and safe products. On the contrary, conventional farmers operate with scattered production and distribution networks, which frequently result in food scandals, fraudulent certification practices, and low consumer trust. The CSA model re-establishes consumer trust and guarantees that products are indeed safe, organically grown, and produced in an environmentally friendly way. In line with Granovetter's [8] notions of embeddedness, formal institutional arrangements can be substituted as well. Examples are the low-cost solutions, such as consumer monitoring, farmer coalitions, or the PGS certification system. This is particularly beneficial for the farmers in this study, who claim that official certification remains too expensive. The shareholder system also aligns the interests of consumers and farmers, and the risks and benefits from a harvest are shared over a larger group of participants. As both consumers and farmers take advantage of the mutual interactions, the CSA model marks an important and less formalized path towards improving the nutritional and safety values in China's food systems. This is especially relevant for China's urban food systems, where the divide between consumer and farmers proves to be most problematic.

\subsection{Structural Embeddedness: The Socio-Spatial Context}

CSA's structural embeddedness is found most evidently in the locality element of the CSA model: the farms operate in the vicinity of the city and products are directly delivered to residents living nearby. This is highly relevant in the context of China's current urban transformation, where population growth and dietary changes are most critical, and consumers are almost entirely dependent on marketed food. Here, CSA caters to urban citizens through a diverse set of distribution channels, including home deliveries, farmers' markets, and online platforms. This has significantly improved the CSA's ability to reach out to a wider group of consumers including non-members, facilitated by an active online presence and media coverage. In addition to reducing the "food miles", the CSA model accords cities greater decision-making powers for their food supplies, and promote resilience to shocks that occur in food markets, such as price hikes or food shortages. Although CSA is not an answer to population growth or dietary changes, direct engagement with the local population makes the model 
more adaptive to evolving dietary needs and provides urban citizens with more influence over the food system.

The socio-spatial context also extends to the interaction with the local environment. Polluted environmental conditions remain a considerable challenge for the CSA farms. This is caused not only by industrialization and urbanization but also because of unsustainable practices in the conventional farming methods. In contrast, CSAs are guided by organic and environmentally-friendly farming methods which aim to improve the local environment. Environmental remediation practices, for instance, can remove pollution and contaminants in soil and groundwater (for a detailed explanation on environmental remediation see [45]). By doing so, CSAs contribute to more sustainable practices that are compatible with future food demands. For instance, much of China's peri-urban farmland is already replaced for non-farming purposes that provide higher economic gains. The CSA model connects farms directly with local communities, urban consumers, local government, and research institutes. In turn, both the economic and social value of farmlands is enhanced. As social capital becomes embedded in farmland, for instance when citizens become members of the farm or rent small plots from the farm, it can contribute to the preservation of farmland. As noted by Brown [20], future food demands can only be assured when a more sustainable use of the environmental resources is accounted for, which is especially relevant in light of China's self-sufficiency policy.

Although proponents of CSA have frequently attached prefixes such as "civic" or "social" agriculture to describe CSA as part of a broader social movement, this study, instead, finds that this dimension of structural embeddedness is constrained by a number of factors (these limitations and contradictions are also found in the earlier studies described in the introduction of this paper. In particular the two studies by Si et al. [16] and Scott et al. [18] point to several inconsistencies between the consumers, producers, and initiators of the Chinese CSA movement). In line with findings by Scott et al. [18], this is partly because the integration and interaction between "new" and local farmers remain low in the current CSA movement. Instead, the current CSA actors are restricted to a small and homogenous segment in China's society. Other groups in society may not see the need for products that are "community-supported" or organically grown. Another significant limitation is the discrepancy between the NRR and the actual CSA practitioners. While the NRR provide ideological motives for CSA, including community inclusion and reducing China's widening rural and urban population gap, the CSAs indicate that both consumers and producers are mostly driven by concerns over healthy and safe food. Here, a possible contradicting outcome may be that CSA, in turn, aggravates inequalities between those that can afford expensive and safer food and those that cannot. Thus, it appears that the broader relational context remains mostly bound within CSA's own domain and remains exclusive to only "a small niche group" [31] rather than the "community". Aside from dealing with the current prevailing challenges, more efforts that go beyond consumer-farmer relations are, thus, required to establish the presence of CSA in China's wider socio-spatial landscape.

\section{Conclusions}

The conventional answer to deal with new challenges to the food system is to focus on economies of scale and intensify the use of chemicals of pesticides, and China's case is no exception. However, with increasing food safety scandals and emerging pressures amidst China's development, there is growing dissatisfaction with China's current food regime. This study demonstrated that alternative approaches, departing from the conventional food system, offer valuable new insights to deal with such emerging issues and adds value to the food system. The CSA model exhibits an innovative approach that touches on the main issues found in China's conventional food system; (i) food safety issues, by re-establishing trust and thereby making more formalized mechanisms abundant; (ii) environmental issues, by introducing organic and environmentally-friendly principles to the farming process; and (iii) meeting the more demanding diets of growing urban populations by operating closely to urban centers and utilizing a diverse set of distribution channels. Yet, this study finds that CSA's recent emergence in China remains mostly reserved to relational embeddedness, i.e., between a homogenous group farmers 
and consumers. In turn, CSA's structural embeddedness is bound by a number of challenges and contradictions, including conflicting motivations and high operational costs. Although the movement is gaining popularity across various parts of China, more efforts are necessary to establish a more attractive and lasting presence in the urban food system.

One of the most important requirements is to make CSA more accessible and bridge the gap between new and local farmers, as both groups currently operate mostly independently. New farmers can benefit from local knowledge and use the land of local farmers, while local farmers can benefit from CSA's innovative farming model, including its marketing and distribution channels. This will provide current farmers and peri-urban farmland with a new stimulus that is urgently needed to address rapid losses of farmland and other challenges in the urban food system. On a final note, although Chinese CSAs claim not to stand in opposition to the politically-envisioned food system-something that is more evident in Western CSAs_contradicting state policies and initiating civil society-led movements always require caution in China's more authoritarian environment. The attitude of the local and central state, therefore, remains to be seen as CSA departs from its initial phase and develops over time and space. Nonetheless, this study suggests that the CSA model illuminates new pathways to ameliorate and add value to prevailing issues that have emerged from China's development.

Acknowledgments: The authors would like to thank the two anonymous reviewers of this journal, as well as Han Wiskerke. Special thanks go to the participants of the International Conference on China Urban Development, University College London, 5-6 May 2017. This research has been partly supported by the China National Natural Science Foundation, project number 71473286 and partly by the European Research Council, RECOLAND GA 282690.

Author Contributions: K.K. performed the fieldwork and wrote the paper; P.H. guided the research, data analysis, and revisions of the manuscript.

Conflicts of Interest: The authors declare no conflict of interest.

\section{References}

1. Hsing, Y. The Great Urban Transformation: Politics of Land and Property in China; Oxford University Press: Oxford, UK, 2010.

2. Lin, G.C.S. Developing China: Land, Politics and Social Conditions; Routledge: New York, NY, USA, 2009.

3. McBeath, J.H.; McBeath, J. Environmental Change and Food Security in China; Springer: Dordrecht, The Netherlands, 2010.

4. Veeck, G. China's Food Security: Past Success and Future Challenges. Eurasian Geogr. Econ. 2013, 54, 42-56.

5. Lang, G.; Miao, B.; Miao, B.O. Food Security for China's Cities. Int. Plan. Stud. 2013, 18, 5-20. [CrossRef]

6. Thompson, D.; Ying, H. Food safety in China: New strategies. Glob. Health Gov. 2007, 2, 1-19.

7. Ernst, M.; Woods, T. Community Supported Agriculture; UK Department of Agricultural Economics: Lexington, KY, USA, 2013.

8. Granovetter, M. Economic Action and Social Structure: The Problem of Embeddedness. Am. J. Sociol. 1985, 91, 481-510. [CrossRef]

9. Harvey, D. Globalization and the "Spatial Fix". Geogr. Rev. 2001, 2, 23-30.

10. Ong, L.H. State-Led Urbanization in China: Skyscrapers, Land Revenue and "Concentrated Villages". China Q. 2014, 217, 162-179. [CrossRef]

11. China Development Research Foundation. China's New Urbanization Strategy; Routledge: London, UK, 2013.

12. World Bank. East Asia's Changing Urban Landscape: Measuring a Decade of Spatial Growth; World Bank: Washington, WA, USA, 2015.

13. Chen, J. Rapid urbanization in China: A real challenge to soil protection and food security. Catena 2007, 69, 1-15. [CrossRef]

14. Zhou, Z. Achieving food security in China: Past three decades and beyond. China Agric. Econ. Rev. 2010, 2, 251-275. [CrossRef]

15. Christiansen, F. Food Security, Urbanization and Social Stability in China. J. Agrian Chang. 2009, 9, 548-575. [CrossRef] 
16. Si, Z.; Schumilas, T.; Scott, S. Characterizing Alternative Food Networks in China. Agric. Hum. Values 2015, 32, 299-313. [CrossRef]

17. Wu, L.; Zhu, D. Food Safety in China; Taylor \& Francis Group: Boca Raton, FL, USA, 2015.

18. Scott, S.; Si, Z.; Schumilas, T.; Chen, A. Contradictions in state- and civil society-driven developments in China's ecological agriculture sector. Food Policy 2014, 45, 158-166. [CrossRef]

19. Wong, J.; Huang, Y. China's Food Security and its Global Implications. China An Int. J. 2012, 10, 113-124.

20. Brown, L. Who Will Feed China: Wake up Call for a Small Planet; Norton and Company: New York, NY, USA, 1995.

21. Ho, P. Institutions in Transition; Oxford University Press: Oxford, UK, 2005.

22. Mai, Y. Removing Border Protection on Wheat and Rice: Effects on Rural Income and Food Self-Sufficiency in China. Aust. J. Agric. Resour. Econ. 2008, 52, 113-131. [CrossRef]

23. Allen, P. Realizing justice in local food systems. Camb. J. Reg. Econ. Soc. 2010, 3, 295-308. [CrossRef]

24. DeLind, L.B. Are local food and the local food movement taking us where we want to go? Or are we hitching our wagons to the wrong stars? Agric. Hum. Values 2011, 28, 273-283.

25. Koscica, M. Agropolis: The Role of Urban Agriculture in Addressing Food Insecurity in Developing Cities. J. Int. Aff. 2014, 67, 177-187.

26. Cheng, C.; Shi, Y. Food safety concerns encourage urban organic farming. In Chinese Research Perspectives on the Environment, Volume 3: Public Action and Government Accountability; Jianqiang, L., Ed.; Brill Publishers: Leiden, The Netherlands, 2014; pp. 133-145.

27. White, T. Growing Diverse Economies through Community Supported Agriculture. Northeast. Geogr. 2013, 5, $1-25$.

28. Shi, Y.; Cheng, C.; Lei, P.; Wen, T.; Merrifield, C. Safe food, green food, good food: Chinese Community Supported Agriculture and the rising middle class. Int. J. Agric. Sustain. 2011, 9, 551-558. [CrossRef]

29. Song, Y.; Zhang, Y.; Buckley, L. Linking rural farmer cooperatives with urban restaurants in Guangxi. In Multiple Pathways: Case Studies of Sustainable Agriculture in China; Buckley, L., Cook, S., Eds.; IIED: London, UK, 2015; pp. 67-82.

30. Cai, J.; Yang, Z.; Liu, S.; Liu, M.; Guo, H.; Du, S. Urban agriculture development in Minhang, Shanghai. Urban Agric. Mag. 2011, 60-62.

31. Buckley, L. Food, farmers and community: A case study of Shared Harvest CSA. In Multiple Pathways: Case Studies of Sustainable Agriculture in China; IIED: London, UK, 2015; pp. 83-100.

32. Creswell, J. Research Design: Qualitative, Quantiative and Mixed Methods Approaches, 4th ed.; Sage: Thousand Oaks, CA, USA, 2003.

33. Velhovar, V.; Manfreda, K.L. Overview: Online sureys. In The SAGE Handbook of Online Research Methods; Fielding, N., Lee, R.M., Blank, G., Eds.; Sage: London, UK, 2008; pp. 177-194.

34. Polanyi, K. The Great Transformation: The Political and Economic Origins of Our Time; Beacon Press: Boston, MA, USA, 1944.

35. Penker, M. Mapping and measuring the ecological embeddedness of food supply chains. Geoforum 2006, 37, 368-379. [CrossRef]

36. Migliore, G.; Schifani, G.; Guccione, G.D.; Cembalo, L. Food Community Networks as Leverage for Social Embeddedness. J. Agric. Environ. Ethics 2014, 27, 549-567. [CrossRef]

37. Sage, C. Social Embeddedness and Relations of Regard: Alternative "Good Food" Networks in South-West Ireland. J. Rural Stud. 2003, 19, 47-60. [CrossRef]

38. Higgins, V.; Dibden, J.; Cocklin, C. Building alternative agri-food networks: Certification, embeddedness and agri-environmental governance. J. Rural Stud. 2008, 24, 15-27. [CrossRef]

39. Sonnino, R.; Marsden, T. Beyond the divide: Rethinking relationships between alternative and conventional food networks in Europe. J. Econ. Geogr. 2006, 6, 181-199. [CrossRef]

40. Kloosterman, R.C. Matching opportunities with resources: A framework for analysing (migrant) entrepreneurship from a mixed embeddedness perspective. Entrep. Reg. Dev. 2010, 22, 25-45. [CrossRef]

41. Krippner, G.R. The Elusive Market: Embeddedness and the Paradigm of Economic Sociology. Theory Soc. 2001, 30, 775-810. [CrossRef]

42. Gottdiener, M.; Hutchison, R. The New Urban Sociology, 4th ed.; Westview Press: Boulder, CO, USA, 2011.

43. Hyde, M.; Syed, F. China's Food Self-Sufficiency Policy. Agric. Commod. 2014, 4, $22-32$. 
44. May, C. PGS Guidelines: How Participatory Guarantee Systems Can Develop and Function; IFOAM: Bonn, Germany, 2008.

45. Eckerd, A.; Keeler, A.G. Going green together? Brownfield remediation and environmental justice. Policy Sci. 2012, 45, 293-314. 